JURNAL SOSAINS

JURNAL SOSIAL DAN SAINS

VOL 2 NO 22022

P-ISSN 2774-7018, E-ISSN 2774-700X

\title{
ANALISIS HUKUM TERHADAP TRANSAKSI MUAMALAH DENGAN MENGGUNAKAN DINAR DAN DIRHAM DI INDONESIA
}

\author{
Siti Umi Kulsum \\ Fakultas Hukum, Universitas Merdeka Malang, Indonesia \\ Corresponding Author : Siti Umi Kulsum \\ Email : umikultsumwht@gmail.com
}

Info Artikel :

Diterima : 25 Januari 2022

Disetujui :

Dipublikasikan :

\begin{abstract}
ABSTRAK
Latar Belakang : Transaksi muamalah dengan menggunakan dinar dan dirham

Kata Kunci:

Transaksi

Muamalah,

Dinar, Dirham merupakan kegiatan ekonomi yang dipraktekan oleh kelompak masyarakat di beberapa daerah yang memiliki pandangan bahwa kegiatan ini adalah bagian dari implementasi menjalankan muamalah berdasarkan prinsip syariah yang sebenarnya. Tujuan : Tujuan penelitian ini adalah untuk melakukan analisis hokum transaksi menggunakan dinar dan dirham. Metode : Penelitian ini merupakan penelitian normatif dengan menggunakan pendekatan konseptual (conseptual approach) dan pendekatan undang-undang (statue approach) Transaksi muamalah dengan menggunakan dinar dan dirham belum ada aturan hukum yang dirumuskan dalam bentuk undang-undang. Hasil : Undang-undang No 7 tahun 2011 Tentang Mata Uang tidak tepat apabila menjadi landasan hukum larangan terhadap penggunaan dinar dan dirham dalam transaksi muamalah. karena pasal-pasal yang tercantum dalam undangundang tersebut apabila di tafsirkan secara rinci dan kritis maka kegiatan muamalah dengan menggunakan dinar dan dirham tidak termasuk dalam unsur pidana. Kesimpulan : UU No 1 tahun 1946 dan UU No 7 Tahun 2011 Tentang Mata Uang tidak dapat dijadikan landasan hukum yang digunakan untuk mendakwakan pelaku transaksi muamalah dengan menggunakan dinar dan dirham sebagai alat transaksi sebagai tindak pidana.
\end{abstract}

Keywords: Muamalah Transactions Dinars, Dirhams

\section{ABSTRACT}

Background : Muamalah transactions using dinars and dirhams are economic activities practiced by community groups in several areas who have the view that this activity is part of the implementation of running muamalah based on actual sharia principles. Purpose : The purpose of this study is to conduct a legal analysis of transactions using dinars and dirhams. Method : This research is a normative research using a conceptual approach (conceptual approach) and a legal approach (statue approach) Muamalah transactions using dinars and dirhams have no legal rules formulated in the form of law. Results : Law No. 7 of 2011 concerning Currency is inappropriate if it becomes the legal basis for prohibiting the use of dinars and dirhams in muamalah transactions. because the articles contained in the law if interpreted in detail and critically, muamalah activities using dinars and dirhams are not included in the criminal element. Conclusion : Law No. 1 of 1946 and Law No. 7 of 2011 concerning Currency cannot be used as a legal basis used to indict the 


\section{Analisis Hukum Terhadap Transaksi Muamalah dengan Menggunakan Dinar dan Dirham di Indonesia}

perpetrators of muamalah transactions using dinars and dirhams as transaction tools as criminal acts.

\section{PENDAHULUAN}

Mengenai asal-usul kata benda dirham Arab Anwar mengatakan bahwa dirham berasal dari Persia atau Yunani, atau dari kedua kota. Dirham pula dibuat dari perak dan diambil dari nama unit mata uang perak yang digunakan oleh penduduk Sasan di Persia (Khalieda, 2017). Dirham juga berasal dari Yunani yaitu drachma yang mempunyai arti timbangan dan mata uang. Perkembangan selanjutnya pada masa kejayaan Islam, Dinar dan Dirham mencantumkan kata-kata atau kalimat teologis Islam dengan beberapa alasan seperti, melambangkan tauhid Islam. Menunjukkan ekonomi Islam dan stabilitas moneter. Mengingat Allah adalah pencipta alam semesta dan kausalitas untuk semua manusia. Maka yang dimaksud dengan dinar adalah mata uang koin yang terbuat dari emas, sedangkan dirham mata uang yang terbuat dari perak (Kusuma, 2018).

Uang merupakan inovasi besar dalam peradaban perekonomian dunia. Posisi uang sangat strategis dalam sebuah perekonomian (Endriani, 2015). Bisa dikatakan uang merupakan bagian yang terintregasi dalam suatu sistem ekonomi, dalam sistem perekonomian, fungsi utama uang adalah sebagai alat tukar (Medium of exchange) (Affandi, 2020). Dari fungsi utama ini, diturunkan fungsi-fungsi yang lain seperti uang sebagai satuan Hitung (unit of Account), penyimpa nilai (Store of Value), Standar Pembayaran di masa mendatang (Standard of Defferent Payment).

Uang sebagai alat tukar adalah uang diterima dan mendapat jaminan kepercayaan. Dalam perekonomian modern ini, jaminan kepercayaan itu diberikan oleh pemerintah berdasarkan Undang-undang atau keputusan yang berkekuatan hukum (Pursetyowati \& Rahmawati, 2015). Sedangkan yang dimaksud uang sebagai satuan hitung adalah uang dapat memberikan harga suatu komoditas berdasarkan satu ukuran umum (Ilyas, 2016). Uang juga sebagai penyimpan nilai dikaitkan dengan kemampuan uang menyimpan hasil transaksi atau pemberian yang meningkatkan daya beli, sehingga semua transaksi tidak perlu dihabiskan saat itu juga (Anggarini, 2016). Selain itu uang memiliki fungsi standar pembayaran di masa mendatang, yaitu dengan uang berapa jumlah balas jasa atau pembayaran di masa mendatang menjadi lebih mudah dihitung, karena diukur dengan daya beli (purchasing power), dibanding bila diukur dengan nilai komoditas tertentu (Novitasari, 2018).

Dari sudut pandang ekonom, uang (money) merupakan stok aset-aset yang digunakan untuk transaksi (Anggarini, 2016). Uang adalah sesuatu yang diterima atau dipercaya masyarakat sebagai alat pembayaran atau transakasi. Karena itu uang dapat berbentuk apa saja, tetapi tidak berarti segala sesuatu itu adalah uang (Faisal, Wahid, \& Yuliani, 2019). Misalnya, saat ini telah dikenal dan digunakan uang kertas yang digunakan sebagai alat transaksi, tetapi tidak semua kertas adalah uang, bukan karena harga kertasnya yang sangat murah, melainkan karena tidak diterima/dipercaya oleh masyarakat umum sebagai alat pembayaran.

Dalam Islam, apa pun yang berfungsi sebagai uang, maka fungsinya hanyalah sebagai medium of exchange. Ia bukan suatu komoditas yang bisa diperjualbelikan dengan kelebihan baik secara on the spot maupun bukan. Satu fenomena penting dari karakteristik uang adalah bahwa ia tidak diperlukan untuk dikonsumsi, ia tidak diperlukan untuk dirinya sendiri, melainkan diperlukan untuk membeli barang yang lain sehingga kebutuhan manusia dapat terpenuhi (Bustaman, 2016).

Dinar dan Dirham sebuah alat pembayaran telah lama dikenal sejak zaman Romawi dan Persia, kedua negara tersebut merupakan dua Negara adidaya yang cukup 
besar pada masa itu. Dinar terbuat dari emas dan Dirham terbuat dari perak. Pada masa kini, walaupun harga emas tetap masih tinggi, uang logam emas dan perak tidak lagi digunakan sebagai alat transaksi, karena kedudukannya telah digantikan oleh bentukbentuk uang yang lain.

Emas sebagai mata uang telah di praktikkan pada Masa Nabi Muhammad SAW, pada saat itu mata uang yang digunakan untuk transaksi adalah emas dan perak hingga runtuhnya Bani Ustmaniyah Turki 1924. Sepanjang kehidupannya Nabi SAW tidak merekomendasikan adanya perubahan apa pun terhadap mata uang. Tujuan penelitian ini adalah untuk melakukan analisis hokum transaksi menggunakan dinar dan dirham.

\section{METODE PENELITIAN}

Sesuai dengan permasalahan dan tujuan penelitian ini, maka jenis penelitian yang digunakan adalah hukum normative atau penelitian hukum doctrinal karena penelitian ini dilakukan dengan mengkaji pada peraturan-peraturan yang tertulis atau bahan-bahan hukum yang lain. Adapaun pendekatan dalam penelitian ini yaitu pendekatan undangundang (status approach) yaitu penelitian terhadap produk-produk hukum. pendekatan yang dilakukan dengan menelaah undang-undang dan regulasi yang berkaitan dengan penelitian yang akan diteliti, sehingga dapat dikatakan sebagai; library based, focusing on reading and analysis of the primary and materials. Penelitian dengan pendekatan analisis terhadap bahan hukum adalah untuk mengetahui makna yang terkandung oleh istilahistilah yang digunakan dalam aturan perundang-undangan berdasarkan konsepsi, sekaligus mengetahui implementasi dalam praktek dan putusan-putusan hukum.

Pendekatan Konseptual (coseptual approach), pendekatan ini dilakukan karena memang belum ada aturan hukum untuk masalah yang dihadapi, pendekatan konseptual ini beranjak dari pandangan-pandangan dan doktrin-doktrin yang berkembang dalam ilmu hukum, sehingga melahirkan pengertian hukum dan asas-asas hukum yang relevan dengan permasalahan yang dihadapi.

\section{HASIL DAN PEMBAHASAN}

\section{A. Penerapan Transaksi dengan Dinar Dan Dirham Berdasarkan Prinsip Syariah di Indonesia}

Dinar dan dirham merupakan salah satu alat transaksi yang stabil. Dinar dan dirham sudah terbukti kestabilan dan keunggulanya untuk bertransaksi apapun. Kestabilan dinar dan dirham, sebenarnya telah diakui juga oleh dunia. Contohnya ketika Amerika serikat menggunakan uang standar emas tahun 1879, tingkat inflasi menurun drastic menyamai tingkat inflasi tahun 1861. Mata uang yang tidak memiliki nilai intrinsic suatu saat akan hancur dalam waktu yang singkat, seperti negara kita yang mengalami krisis yang berkepanjangan tahun 97-98 sampai sekarang (Sakty, 2012). Maka solusinya adalah menyatukan umat dalam bertransaksi muamalahnya dengan menggunakan dinar dan dirham. Nilai ini dapat mengembalikan kejayaan dan kemakmuran umat. Melihat pentingnya kemanfaat dinar dan dirham tersebut organisasi penngerakan dinar dan dirham sudah lama mengsosialisasikan alat transaksi tersebut.

Perlu di pahami bahwa penggunaan dinar dan dirham bukanlah suatu keawjiban dalam islam, namun mayoritas ulama berpendapat bahwa dinar dan dirham disyariatkan (dilegalkan) dalam islam dan hukumnya boleh (mubah). Meskipun bukan suatu kewajiban menggunakan dinar dan dirham dalam transaksi, tetapi sejarah membuktikan bahwa menggunakan dinar dan dirham tidak menimbulkan masalah. Bahkan kemakmuran hidup dapat tercapai karena kestabilan ekonomi yang terjaga. Nilai mata 
uang yang tidak distandarkan kepada emas dan perak maka nilainya akan turun. Inilah yang disebut dengan inflasi, di Indonesia praktek transaksi dengan menggunakan dinar dan dirham terdapat pada:

1. Pasar Muamalah

Pasar muamalah merupakan pasar tradisional yang berbeda dengan pasar pada umumnya. Pasar muamalah ini sudah berdiri sejak tahun 2009, sampai saat ini egiatan pasar muamalah ini sudah berkembang di beberapa daerah yaitu : Depok, Yogyakarta, ketapang, Kalimantan barat, tanjung pinang, pulau bintan, dan kepulauan riau. Pasar ini dinamakan pasar muamalah karena menerpakan unsur-unsur syariah di dalamnya. Dalam pasar mamalah ini alat transaksi yang digunakan aktifitas jual beli tidak menggunakan rupiah melainkan dinar dan dirham.

Seperti pada umumnya kegiatan dalam pasar muamalah ini meliputi kegiatan jual beli dan sewa menyewa dalam pasar. Kegiatan jual beli dapat diartikan sebagai pertukaran barang dengan barang yang lain atau dengan harga yang sesuai atas dasar saling ridho atau kesepakatan. Secara hukum fiqh jual beli merupakan kepemilikan harta benda dengan jalan tukar menukan berdasarkan aturan syariat.

Adapun dalam transaksi pasar muamalah ini telah menerapkan prinsip-prinsip muamalah dalam jual yaitu menghindari hal-hal yang menimbulkan transaksi tidak sah.

a. Ketidakjelasan akad

b. Pemaksaan.

c. Pembatasan dengan waktu

d. Penipuan

e. Kemudharatan

Secara umum kegiatan di pasar muamalah sudah sesuai dengan prinsip muamalah

a. Kebolehan dalam melakukan aspek muamalah, baik jual beli maupun sewa menyewa ataupun lainya. Dasar hukum fiqihnya : prinsip dasar muamalah adalah boleh kecuali ada dalil yang mengharamkanya.

b. Kegiatan muamalah didasarkan atas pertimbangan membawa kemaslahatan atau kebaikan dan menolak segala yang merusak. Hal ini selaras dengan tujuan diturunkanya syariah adalah sebagaiman Alsyaitabi menyebukan ada lima hal yaitu agama, jiwa, keselamatan akal, harta dan keturunan.

Adapun model transaksi pada pasar muamalah yaitu

a. Jual beli

b. Sewa menyewa

c. Menggunakan dinar dan dirham sebagai alat transaksi pembayaran

d. Pembeli masih bisa menggunakan rupiah untuk transaksi selama pedagang dan pembeli saling ridho

e. Pengelola pasar muamalah tidak memaksa pedagang atau pembeli bertransaksi dengan uang tertentu baik dinar maupun dirham, transaksi bisa dilakukan dengan cara barter, baik memakai rupiah atau dinar dirham selama pembeli dan penjual sama-sama saling ridho.

2. Koperasi (BMT Darul Muttaqiin)

Praktek transaksi dengan menggunakan dinar dan dirham yang diterapkan di BMT Daarul Muttaqiin telah memiliki dasar hukum, baik untuk BMT sendiri maupun untuk nasabah BMT, sesuai dengan peraturan Bank Indonesia nomor 16/16/PBI/2014 tentang transaksi valuta asing terhadap rupiah antara bank dengan pihak domestic pada bab 1 tentang ketentuan umum pasal 1 nomor 2 bahwa badan usaha selain Bank yang berbadan hukum Indonesia, berdomisili di Indonesia, dan memiliki Nomor Pajak Wajib Pajak (NPWP) serta perorangan yang memiliki kewarganegaraan Indonesia.sedangkan untuk produk BMT tentang M-Dinar juga sesuai dengan dasar hukum baik hukum negara 
ataupun hukum syar'i, sesuai dengan peraturan bank Indonesia nomor 16/16/PBI/2014 tentang transaksi valuta asing terhadap rupiah antara bank dengan pihak domestik pada bab 1 tentang ketentuan umum pasal 1 nomor 3 transaksi valuta asing terhadap rupiah adalah transaksi jual beli valuta asing terhadap rupiah dalam bentuk:

1. Transaksi spot, merupakan transaksi yang dilakukan dengan valuta today dan/atau valuta tommorrow

2. Transaksi derivative valuta asing terhadap rupiah standar (plan vanilla) dalam bentuk forward, swap, option, dan transaksi lainya yang dipersamakan dengan itu.

BMT Darul Muttaqin dalam menerapkan transaksi berdasarkan prinsip syariah telah menerapkan Aqad Mudharobah, Wadi'ah, dan Ashorf.

1. Mudharobah

Mudharobah adalah aqad yang telah dikenal oleh umat muslim sejak zaman nabi, mudharobah disebut juga qirodh atau muqorodhah atau muamalah, menurut para ulama fiqih perbedaan tersebut terletak pada kebiasaan penyebutan dari masing-masing daerah islam. Menurut fatwa DSN-MUI yang ditandatangani oleh K.H Alie Yafie sebagai ketua dan Nazri Adlani sekertais pada tanggal 1 April 2000 tentang bagi hasil dengan cara mudhrobah adalah aqad kerjasama suatu usaha antara dua pihak, pihak pertama menyediakan seluruh modal, sedangkan pihak kedua bertindak selaku pengelola dan keuntungan usaha dibagi di antara mereka sesuai kesepakatan yang dituangkan dalam kontrak.

2. Wadi'ah

Wadi'ah berasal dari kata Al Wadi'ah yang berarti titipan murni (amanah) dari satu pihak ke pihak yang lain, baik individu maupun badan hukum, yang harus dijaga dan dikembalikan kapan saja si penitip menghendakinya.

Secara istilah, wadi'ah berarti mewakilkan penjagaan suatu harta yang special atau yang bernilai tertentu dengan cara tertentu. Al Bahuti Mansyur mendefenisikan wadi;ah sebagai pemberian kuasa oleh penitip kepada orang yang menjaga hartanya tanpa kompensasi (ganti rugi).

Prinsip al Wadi'ah dalam bank syariah merujuk pada perjanjian dimana pelanggan menyimpan harta di bank dengan tujuan agar bank bertanggungjawab menjaga harta tersebut dan menjamin pengembalian harta tersebut apabila terjadi tuntutan dari nasabah. Sebagai konsekuensi dari pelaksanaan prinsip wadi'ah adalah semua keuntungan yang dihasilkan dari dana titipan tersebut akan menjadi milik bank (demikian pula ebaliknya). Sebagai imbalan dari nasabah, pihak penyimpan mendapat jaminan keamanan terhadap harta dan fasilitas-fasilitas giro lain.

3. Ashraf

Assharf adalah perjanjian jual beli suatu valuta asing dengan valuta lainya. Menurut Wahbah alzhaili mengatakan, Al sharf ialah pertukaran mata uang dengan mata uang lainya baik satu jenis maupun jenis lain, seperti uang dollar dengan uang rupiah, atau uang rupiah dengan dinar dinar dan dirham.

Transaksi muamalah di dengan menggunakan dinar dan dirham telah memberlakukan tahapan-tahapan yang telah dijelaskan diatas dalam pembiayaan menggunakan M-Dinar dengan akad mudarobah, wadi'ah dan As shorf agar tehindar dari adanya transaksi gharar atau ketidakjelasan kedua belah pihak dan berdampak pada ketidakadilan.

Para ulama mazdhab sepakat bahwa mudharobah, Ashrof dan wadi'ah hukumnya boleh berdasarkan Al-Qur'an, Sunnah, Ijma' dan qiyas. Hal ini dikarenakan akad mudharobah bertuntuk saling membantu antara pemilik modal dengan sesorang yang ahli dalam meregulasikan uang, begitu pun sebaliknya. Atas dasar itu saling tolong menolong 
dalam pengelolaan modal itu, islam memberikan kesempatan untuk saling bekerja sama antara kedua belah pihak.

\section{B. Analis Hukum transaksi (muamalah) dengan menggunakan Dinar Dan Dirham Di Indonesia}

Analisis ini bertujuan untuk menjawab bagaimana hukum melakukan transaksi muamalah dengan menggunakan dinar dan dirham berdasarkan prinsip syariah di indonesia. Untuk menjawab persoalan tersebut penulis berusaha untuk menganalis dari berbagai pandangan hukum yang berlaku di Indonesia. Analisis ini juga di dasarkan pada pendapat para ahli dalam literasi dan jurnal yang berkaitan dengan hukum islam maupun hukum positif.

\section{Presektif Hukum Islam}

a. Dasar Alqur'an

Berdasarkan hukum Islam, Istilah uang (emas/perak) termuat dalam Alqur'an seperti berkaitan dengan dinar (Qs. Ali-Imran 3:7) dan dirham (QS.Yusuf 12:20), bahkan nabi sendiri menggunakan uang emas dan perak dalam bermuamalah. Penggunaan dinar dirham oleh nabi dan para sahabat-sahabatnya serta para pengikutnya generasi salaf inilah yang kemudian terekam dalam system ekonomi Islam klasik hingga beberapa periode sejarah peradaban islam.

Berdasarkan apa yang sudah dijelaskan bahwa dinar dan dirham tercantum dalam Alqur'an dan Rasulullah juga menggunakanya sebagai alat transaksi ini menunjukan adanya kebaikan dan tidak bertentangan dengan islam sehingga layak untuk digunakan. Namun tidak ada hadis yang menyatakan bahwa mata uang haruslah dinar dan dirham. Merujuk pada urf dalam memilih bahan uang merujuk pada kesepakatan para penggunanya. Bahwa menurut imam Malik semua jenis benda niaga yang umum dapat diterima sebagai alat tukar. Ibnu Hazim mengatakan bahwa alat tukar yang digunakan dapat berupa segala sesuatu yang boleh diperjualbelikan.

Menurut pendapat Ibnu Khaldun, uang digunakan sebagai standart nilai, uang tidak harus berupa emas dan perak tetapi harus berfungsi sebagai standart nilai dan nilainya tidak boleh berubah-berubah. Sifat uang yang disampaikan oleh Ibnu Khaldun tersebut ada pada kandungan emas dan perak yang memiliki nilai intrinsic dan kestabilan harga (Munir, 2016). Dinar dan dirham termasuk kategori ayn merujuk pada HR Muslim 1548 dan 1587, dari prespektif agama, dinar dan dirham merupakan bagian dari upaya bermuamalah secara lebih syar'i jika semua itu diniatkan karena Allah ta'ala. Sesuatu yang dibolehkan oleh syariat tentu tidak boleh dilarang selama tidak mengganggu ketertiban umum.

Pada dasarnya dinar dan dirham bukan alat transaksi asli dari bangsa arab. Dua mata uang ini merupakan milik bangsa romawi dan Persia. Ketika islam hadir kemudian diadopsi oleh bangsa arab dijadikan sebagai alat tukar dalam perniagaan. Beberapa pendapat menyatakan alasan bahwa Rasulullah menggunakan dinar dan dirham karena keduanya menjadi nilai yang sesuai dengan intrinsiknya dan nilai yang stabil. Hal ini sesuai dengan literasi dan teori bahwa uang logam yang terbuat dari emas dan perak memenuhi persyaratan sebagai uang yaitu: langka, mempunyai nilai yang tinggi dan dapat diterima masyarakat luas, bebas inflasi tahan lama dan tidak mudah rusak.

Dinar dan dirham memililiki nilai yang intrinsic dan nilainya akan stabil dari zaman ke zaman, di dalam dinar dan dirham terdapat kelangkaan didalam barangnya, teksture dari bendanya padat dan proses pembuatanya sulit sehingga tidak akan terjadi inflasi. Yang menjadi kekuatan masyarakat dunia ekarang adalah inflasi yang menggunakan mata uang tanpa jaminan fiat money. 


\section{Volume 2, Nomor 2, Februari 2022 p-ISSN 2774-7018; e-ISSN 2774-700X}

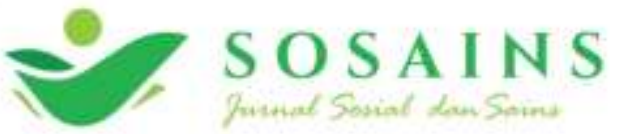

Adanya Fiat money menyebabkan dollar menjadi kiblat mata uang perdagangan Internasional tentu menguntungkan negara-negara besar seperti Amerika yang menciptakan dollar sesuai kehendaknya.

b. Berdasarkan Hadist

Dinar dan dirham merupakan mata uang yang digunakan dengan waktu terlama dalam sejarah perkembangan uang. setelah digunakan dengan waktu yang lama, dinar dirham pada masa Nabi Muhammad SAW diawali sejak bangsa Arab Hijaz. Mereka memperoleh mata uang dari kabilah Quraisy ketika melakukan perdagangan. Dinar yang digunakan adalah dinar Hercules dan Byziantum sedangkan dirhamnya berasal dari Dinasti Sasaniq Iraq. Kemudian pada saat Nabi Muhammad diutus menjadi Rasul menetapkan dan memerintahkan penduduk Madinah agar mengikuti timbangan penduduk Madinah. Penggunaan Dinar dan Dirham mengacu pada Hadist Rosulullah SAW “ Timbangan adalah timbangan penduduk Makkah, dan takaran adalah takaran penduduk Madinah"

2. Berdasarkan UUD 1945

Penggunaan dinar dan dirham sebagai alat transaksi merupakan bagian dari keyakinan agama seseorang dalam ibadah maupun muamalah. Menurut UUD 1945 melarang orang melakukan apa yang diyakini dalam hal ibadah maupun muamalah berarti telah melanggar Pancasila sila ke 1 dan Pasal 29 UUD 1945. Adapun bunyi sila ke 1 Pancasila yaitu "Ketuhanan Yang Maha Esa" dan Pasal 29 UUD 1945, yang berbunyi sebagai berikut :

1. Negara Berdasarkan atas Ketuhanan yang Maha Esa

2. Negara Menjamin kemerdekaan tiap-tiap penduduk untuk memeluk agama masingmasing dan untuk beribadat menurut agamanya dan kepercayaanya itu.

Kandungan yang ada di dalam Pancasila dan Undang-Undang Dasar 1945 inilah yang menjadi alasan bahwa tidak boleh melarang apa yang menjadi keyakinan seseorang dalam beribadah dan bermuamalah. Akan tetapi mata uang yang diakui oleh Negara hanya Rupiah. Maka penggunaan Dinar dan Dirham sebagai alat tukar diperbolehkan apabila berlaku khusus hanya dalam komunitas seperti yang ada dalam pasar muamalah. Dan tidak ada masalah apabila penggunaan Dinar dan Dirham ini disepakati oleh para pihak yaitu penjual dan pembeli (Nurhisam, 2020).

3. KUH Perdata

Kembalinya masyarakat menggunakan dinar dan dirham didasarkan pada UndangUndang KUHPerdata tentang kontrak. Kontrak merupakan sebuah kesepakatan antara dua pihak yang menjalin kesepakatan di dalam perjanjian kontrak tersebut. Jadi pada dasarnya kontrak terdapat sebuah hubungan antara kedua belah pihak tersebut, dimana berisi perjanjian yang mengikat antara para pihak. Menurut pasal 1338 ayat (1) Kitab Undang-Undang Hukum Perdata bahwa seluruh persetujuan yang dibuat secara sah berlaku bagi undang-undang yang membuatnya, selama tidak bertentangan dengan kesusilaan dan ketertiban hukum.

Ketentuan pada pasal tersebut bahwa para pihak diberi suatu kebebasan membuat perjanjian menentukan isi perjanjian beserta persyaratan-persyaratan yang bentuk perjanjianya bisa dilakukan secara tertulis ataupun secara lisan. Sehingga suatu hubungan antara dua orang disebut dengan perikatan. Kebebasan yang diberikan kepada para pihak yang membuat kontrak inilah yang menjadi pokok tujuan bahwa dinar dan dirham boleh dipergunakan secara hukum positif. Dan hai ini tidak melanggar karena tidak diberlakukan secara universal.

Pada saat ini jika dinar dan dirham diberlakukan kembali maka hukumnya boleh selama tidak mengganngu kepentingan orang lain dan tidak memaksa, dasar 
diperbolehkanya karena kesepakatan kedua para pihak yang melakukan transaksi (Yolan, 2021). Arti kesepakatan sendiri ada pada pasal 1320 ayat (1) KUH Perdata yakni “" Persesuaian pernyataan antara satu orang atau lebih dengan pihak lainya" yang mana kesepakatan ini terjadi sesuai apa yang dikehendaki oleh para pihak.

Terjadinya penggunaan dinar dirham sebagai alat transaksi karena kesepakatan dan kehendak para pihak serta kepemilikan emas tidak dilarang oleh negara maka hal ini diperbolehkan meski aturan dalam penggunaanya sebagai alat transaksi belum ada undang-undang yang mengakomodir (Al Arif, 2012). Dalam realitanya penggunaan dinar dan dirham masih tergolang ayn maka jika digunakan untuk membeli barang dan jasa masih tergolong $a^{\prime} y n$ bi $a^{\prime} y n$, jika dinar dan dirham berupa dayn maka tabungan digerai dinar akan menjadi sebuah akun virtual. Selama ini Pemerintah masih pro aktif dalam kegiatan yang dilakukan ini namun tidak didukung dengan kebijakan politik hukum. sehingga pergerakanya akan hanya dalam lingkup komunitas-komunitas tertentu, padahal praktek ini cukup menarik umat-umat yang lain. Tetapi karena tidak ada kelegalan membuat perkembanganya terhambat.

\section{KESIMPULAN}

Sejauh ini belum ada aturan hukum sebagai bentuk perlindungan hukum dalam hal transaksi dengan menggunakan dinar dan dirham. Di era modernism hukum, untuk melindungi hak masyarakat perlu adanya legaitas. Legalitas mutlaq agar ada perlindungan hukum bagi pelaku transaksi menggunakan dinar dan dirham. Untuk menerapkan dinar dan dirham sebagai alat transaksi yang sah maka harus memenuhi berbagai tahapan yuridis. Pertama harus ada fatwa dari DSN MUI Setelah fatwa MUI diterbitkan tahap selanjutnya adalah penyerapan terhadap DSN MUI ke dalam peraturan BI. Apabila peraturan Bank Indonesia sudah terbit maka penggunaan dinar dan dirham telah sah dan legal sebagai alat transaksi.

UU No 1 tahun 1946 dan UU No 7 Tahun 2011 Tentang Mata Uang tidak dapat dijadikan landasan hukum yang digunakan untuk mendakwakan pelaku transaksi muamalah dengan menggunakan dinar dan dirham sebagai alat transaksi sebagai tindak pidana. sebagaimana putusan pengadilan Negeri Depok Nomor 202/Pid.Sus/2021/PN Dpk pada tanggal 12 oktober 2021 pelaku transaksi muamalah dengan menggunakan dinar dan dirham di Indonesia terbukti tidak bersalah.

\section{BIBLIOGRAFI}

Affandi, Faisal. (2020). Fungsi Uang Dalam Perspektif Ekonomi Islam. Eksya: Jurnal Ekonomi Syariah, 1(1), 82-91.

Al Arif, M. Nur Rianto. (2012). Lembaga Keuangan Syariah: Suatu Kajian Teoretis Praktis. Pustaka Setia.

Anggarini, Desy Tri. (2016). Analisa Jumlah Uang Beredar di Indonesia Tahun 20052014. Moneter-Jurnal Akuntansi Dan Keuangan, 3(2).

Bustaman, Bustaman. (2016). Konsep Uang dan Peranannya dalam Sistem Perekonomian Islam (Studi Atas Pemikiran Muhammad Abdul Mannan). makassar: Universitas Islam Negeri Alauddin Makassar.

Endriani, Santi. (2015). Konsep Uang: Ekonomi Islam vs Ekonomi Konvensional. Anterior Jurnal, 15(1), 70-75.

Faisal, Agus, Wahid, Ahmad Nur, \& Yuliani, Irma. (2019). Rekonstruksi Integralistik Instrumen Mata Uang Berbasis Syariah (DIGITAL GOLD CURRENCY). El Dinar: Jurnal Keuangan Dan Perbankan Syariah, 7(2), 100-118. 
Ilyas, Rahmat. (2016). Konsep Uang Dalam Perspektif Ekonomi Islam. BISNIS: Jurnal Bisnis Dan Manajemen Islam, 4(1), 35-57.

Khalieda, Fatma. (2017). Isu-isu Dinar dan Dirham. Al-Intaj: Jurnal Ekonomi Dan Perbankan Syariah, 3(1).

Kusuma, Kumara Adji. (2018). Pengantar Ilmu Ekonomi Islam. Umsida Press, 1-140.

Munir, Misbahul. (2016). Implementasi Integrasi Al-Quran dan Hadits: Analisis Tematik Terhadap Konsep Uang dalam Islam.

Novitasari, Sisilia. (2018). Efektivitas Pasal 34 huruf A peraturan Bank Indonesia Nomor 18/40/Pbi/2016 tentang penyelenggaraan pemrosesan transaksi pembayaran terhadap pelarangan bitcoin sebagai alat pembayaran di Indonesia.

Nurhisam, Luqman. (2020). Bitcoin dalam kacamata hukum islam. Ar-Raniry, International Journal of Islamic Studies, 4(1), 165-186.

Pursetyowati, Sri, \& Rahmawati, Fitria. (2015). Fungsi Jaminan dalam Perjanjian Kredit. Wacana Paramarta: Jurnal Ilmu Hukum, 14(1).

Sakty, Dhian Pramono. (2012). Nilai-nilai Patriotisme dalam Novel Sebelas Patriot Karya Andrea Hirata dan Pemanfaatannya Sebagai Bahan Pembelajaran Sastra di SMA. S1 Thesis Universitas Negeri Yogyakarta, 4.

Yolan, Ilamia Nur Cahani. (2021). Tinjauan Hukum Islam Tentang Hutang Barang Dibayar Dengan Tambahan Biaya (Studi di Toko Ansori Desa Bumisari Kecamatan Natar Kabupaten Lampung Selatan). Lampung: Universitas Islam Negeri Raden Intan Lampung.

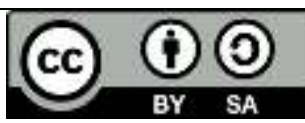

This work is licensed under a Creative Commons Attribution-ShareAlike 4.0 International License. 